\title{
Vygotsky's theory in early childhood education and research. Russian and Western values
}

\section{Hilppö, Jaakko}

2020-10-01

Hilppö , J 2020 , ' Vygotsky's theory in early childhood education and research. Russian and Western values ' , Mind, Culture, and Activity , vol. 27 , no. 4 , pp. 373-375 . https://doi.org/10.1080/10749039.2020.

http://hdl.handle.net/10138/336568

https://doi.org/10.1080/10749039.2020.1830114

acceptedVersion

Downloaded from Helda, University of Helsinki institutional repository.

This is an electronic reprint of the original article.

This reprint may differ from the original in pagination and typographic detail.

Please cite the original version. 
Vygotsky's Theory in Early Childhood Education and Research

Russian and Western Values, Edited by Nikolay Veraksa \& Sonja Sheridan, New York, NY: Routledge, 2018, 219 pp., £96 (hardcover)

Jaakko Hilppö

University of Helsinki

Imagine a drop of water. Next, imagine placing that drop of water on your knuckle and watching it roll down your hand. Then, a second drop of water. And a third. Each new drop might well follow the route of the previous one, but occasionally it diverges and takes a new path down your hand. Imagine now that, instead of water, the drops are studies on early childhood education and care (ECEC) based on the work of Lev Vygotsky, and that you are following how his work is implemented in different contexts around the world. Although sharing the same foundation and following similar lines of argumentation, each study is unique and shines new light on the original work of Vygotsky as well as on possible new directions it could take.

Understanding how Vygotsky's work has been applied across different studies in education is the goal Nikolay Veraksa (Russian Academy of Education) and Sonja Sheridan (University of Gothenburg, Sweden) set for themselves in their new edited book. They write in the introduction: "Today is not so much a question of the discovery of [Vygotsky's, my edit] ideas as of their interpretation and application" (p. 6) and seeing the "possible prospects for the development of Vygotsky's ideas in educational culture” (p. 3). As implied in the subtitle of the book, Veraksa and Sheridan's specific focus is comparative, aimed at highlighting how different value systems (in this case Russian and Western) emphasize and apply Vygotskian theory in varying ways. Given the relevance of Vygotsky's work for ECEC practice as well as the increasing volume and growing impact of research on the global level (e.g., OECD, 2006), this is a worthy and interesting effort. The fact that similar edited volumes with a combined focus on Vygotsky and ECEC are somewhat of a rarity further accentuates the importance of this goal (and the book).

Indeed, Veraksa and Sheridan have assembled an impressive group of scholars in early childhood education who build on and apply cultural-historical theory in conducting original research and in designing for different early-childhood contexts. Among the contributors are names that readers of literature on Mind, Culture and Activity will recognize (e.g., Ingrid Pramling Samuelsson, Nikolay Veresov, ...). Significantly, however, there are also names that might be less familiar, albeit these scholars are established in their own countries. In this sense the book already delivers. A new ensemble of authors provides new perspectives and potential for comparison. The chapters that draw on studies conducted in Russia will be especially interesting to those who are less familiar with Russian ECEC research and practice. For those who are already cognizant of the Russian context, in turn, the chapters that contrast Swedish and Russian or Mexican and Australian ECEC contexts, for example, will probably be more enticing.

The book is organized around three themes: children's cognitive learning and development, interaction and communication, and play and physical activities. The most substantial of these is the first one, which is addressed in eight individual chapters. The other two themes each have three chapters. Most, but not all of the chapters draw on different case studies conducted in various contexts of early childhood education. Those that focus on children's leisure time (Sobkin, Skobeltsina, van Oudenhoven) and soccer practice (A. Veraksa, Quintino Aires, Leonov, Mu'salek) are especially interesting given that they highlight children's life outside kindergartens or early childhood centers, where ECEC research is predominantly conducted. In addition to covering the main themes, Veraksa and Sheridan contribute an introduction and a closing chapter in which they give an overview of and compare the contributions of the individual chapters and discuss the ways in which Vygotsky's work and cultural-historical theorizing more broadly have been implemented in Russia and the West. Two of the chapters echo and further contextualize the comparisons made 
elsewhere in the book. Säljö and Veraksa summarize their understanding of the central tenets of Vygotsky's work and how they have been adopted in Russia and the West, whereas Sheridan, Shiyan and Shiyan compare and discuss preschool quality in both Russia and Sweden.

The book makes a solid contribution to the field of cultural-historical research. The individual chapters fit together well and form a coherent but diverse collection of studies. Regarding their goal, Veraksa and Sheridan's main conclusion is that Vygotsky's theory and concepts constitute a point of convergence for ECEC scholars globally engaged in discussing children's learning and development during preschool age. They point out the relevance of this convergence in terms of highlighting differences among educational systems, their goals and inherent values. Russian studies of children's play in preschool, for example, show that adults are more active in organizing and leading activities, whereas Western studies emphasize spontaneity and children's active role in guiding the play. Veraksa and Sheridan discuss these differences following familiar fault lines, pointing out that Russian studies make explicit how the Russian educational system values the leading role of teachers in organizing children's activities and guiding them in cultural matters. In contrast, Western studies highlight the importance of individual freedom and the role of adults in supporting children to become self-governing subjects of democratic societies. Although the validity of such grand-scale cultural categories could be called into question, they nevertheless serve Veraksa and Sheridan's purpose and show the potential value of Vygotskian comparative studies (be they national or international) in generating insights and discoveries, not just about children's learning and development but also concerning the complex societal systems that support, channel and facilitate them. In this respect, the book continues the stream of comparative studies that have been at the heart of cultural-historical research from the very beginning (for example, Vygotsky's and Luria's expeditions in Central Asia; Cole \& Scribner, 1974; Saxe \& Esmonde, 2005), and expands the focus to ECEC education systems and their axiological underpinnings.

On a more personal level, one of the main takeaways from the book for me is the presentation of various studies on children's dialectical thinking in ECEC contexts. The dialectical roots of cultural-historical theorizing are more generally understood, but the different forms that dialectical thinking can assume in children's thinking and overall, I would argue, are less so. In this sense, the overview that Säljö and Veraksa provide, as well as the individual chapters that focus on this issue, are highly illuminating. Not only do they explain dialectical thinking theoretically, they also provide various examples of how such thinking in children can be studied through narratives or drawings, for example. I would imagine that, in addition to arousing the interest of other ECEC researchers, these chapters also provide a stepping stone for new studies on dialectical thinking in early-years education.

Although there is a great deal to appreciate in the book, there are also parts and aspects that leave the reader hoping for additional clarity and precision. For example, there is a noticeable difference between the chapters in how they argue for and show the contribution of their particular study. All the authors acknowledge and base their work on cultural-historical theorizing, but the rationale for their particular focus and how their work furthers this theorizing is not always clear. Furthermore, some of the same concepts are occasionally worded differently in different chapters, and there are passages within individual chapters that would have benefitted from a more rigorous editorial process, in relation to both substance and language. This makes the book and its contribution harder to grasp. A more uniform presentation would have made the book more accessible to its readers on the whole. Yet, in some sense these differences feel befitting to the goal of the book. Like the ECEC practices and systems analyzed in the book, academic cultures also have their relative differences and idiosyncrasies, and just not exclusive to how research is presented and argued for. As also with ECEC, there is not a single "right" solution to how such practices or systems should be organized, but rather a plurality of them. In this sense, Veraksa and 
Sheridan's book also showcases, in a minor way, differences between academic cultures of today's Vygotskian ECEC scholarship in a way that serves the goal of their book.

The potential audience for the book is wide and varied. In addition to speaking directly to researchers interested in the application of cultural-historical theory in various cultural contexts, it should also appeal to ECEC researchers more broadly. In its entirety it could easily form part of the syllabus for Bachelor's and Master's studies, especially in curricula with a focus on ECEC or learning and development during early childhood in general. The individual chapters naturally serve a broader range of interests. A further use for the book would be in the field of professional development, specifically in early childhood education, either as self-selected reading or as part of a course.

Overall, Veraksa and Sheridan, with their co-authors, have delivered a good book that gets the European Early Childhood Education Research Association's (EECERA) new research monograph venture off to a fine start.

\section{References}

Cole, M. \& Scribner, S. (1974). Culture and Thought: A Psychological Introduction. John Wiley \& Sons.

OECD. (2006). Starting Strong II: Early Childhood Education and Care. OECD, Paris.

Saxe, G. B., \& Esmonde, I. (2005). Studying cognition in flux: A historical treatment of Fu in the shifting structure of Oksapmin mathematics. Mind, Culture, and Activity, 12(3-4), 171-225. 